\title{
Microneedle-Based Transcutaneous Immunisation in Mice with N-Trimethyl Chitosan Adjuvanted Diphtheria Toxoid Formulations
}

\author{
Suzanne M. Bal • Zhi Ding • Gideon F. A. Kersten • Wim Jiskoot • Joke A. Bouwstra
}

Received: 8 April 2010 / Accepted: 28 May 2010 / Published online: 18 June 2010

(C) The Author(s) 2010. This article is published with open access at Springerlink.com

\begin{abstract}
Purpose The purpose of this study was to gain insight into the delivery and immunogenicity of $\mathrm{N}$-trimethyl chitosan (TMC) adjuvanted diphtheria toxoid (DT) formulations applied transcutaneously with microneedles.

Methods Mice were vaccinated with DT-loaded TMC nanoparticles, a solution of TMC and DT (TMC/DT) or DT alone. The formulations were applied onto the skin before or after microneedle treatment with two different 300- $\mu$ m-long microneedle arrays and also injected intradermally (ID). As a positive control, alum-adjuvanted DT (DT-alum) was injected subcutaneously (SC). Ex vivo confocal microscopy studies were performed with rhodamine-labelled TMC.

Results Independent of the microneedle array used and the sequence of microneedle treatment and vaccine application, transcutaneous immunisation with the TMC/DT mixture elicited 8-fold higher IgG titres compared to the TMC nanoparticles or DT solution. The toxin-neutralising antibody titres from this group were similar to those elicited by SC DT-
\end{abstract}

Electronic Supplementary Material The online version of this article (doi: | 0. I 007/s | | 095-0 I0-0 | 82-y) contains supplementary material, which is available to authorized users.

S. M. Bal $\cdot$ Z. Ding $\cdot$ W. Jiskoot $\cdot J$. A. Bouwstra

Division of Drug Delivery Technology, Leiden/Amsterdam

Center for Drug Research, Leiden University,

Leiden, The Netherlands

G. F. A. Kersten

Department of Research and Development,

Netherlands Vaccine Institute,

Bilthoven, The Netherlands

\section{J. A. Bouwstra $(\square)$}

Division of Drug Delivery Technology, Leiden/Amsterdam Center

for Drug Research, Leiden University,

PO Box 9502, 2300 RA Leiden, The Netherlands

e-mail: bouwstra@lacdr.leidenuniv.nl alum. After ID immunisation, both TMC-containing formulations induced enhanced titres compared to a DT solution. Confocal microscopy studies revealed that transport of the TMC nanoparticles across the microneedle conduits was limited compared to a TMC solution.

Conclusions In conclusion, TMC has an adjuvant function in transcutaneous immunisation with microneedles, but only if applied in a solution.

KEY WORDS diphtheria toxoid - microneedles .

nanoparticles · transcutaneous immunisation · trimethyl chitosan (TMC)

\section{INTRODUCTION}

Transcutaneous immunisation (i.e. immunisation through vaccine application onto the skin) has the potential to be an excellent non-invasive vaccination route (1). This is desirable as injection of a vaccine with a needle and a syringe is not only painful (2), but it also bears a risk of transmission of infection with, e.g., hepatitis $\mathrm{B}$ or $\mathrm{C}$, or human immunodeficiency virus (3). Furthermore, the skin is densely populated with antigen presenting cells (APCs) (4). In the epidermis the Langerhans cells (LCs) are present, and in the dermis the dermal dendritic cells (DCs) $(5,6)$. The main function of these professional APCs is to sample their environment, process antigens and present specific epitopes to $\mathrm{T}$ cells. Studies using intradermal (ID) immunisation (i.e. injection of the antigen into the dermis) have shown that this delivery route can result in similar or even enhanced immune responses compared to intramuscular immunisation $(7,8)$.

During recent years, particle-based immunisation has gained more emphasis (9). The advantage of nanoparticles is that they can function as a depot (10) and are more 
efficiently taken up by DGs than plain antigens (11). Therefore, nanoparticles may function as an adjuvant. Nanoparticles can be prepared from polymers, such as poly (DL-lactic-co-glycolic acid) (PLGA) or N-trimethyl chitosan (TMC). TMC is a derivate of chitosan that bears a permanent positive charge and is therefore water soluble over a wide $\mathrm{pH}$ range. TMC nanoparticles have mainly been used in mucosal immunisation (12-14), but recently we showed that TMC can also function as an immune potentiator in ID immunisation (15). Interestingly, we observed that the adjuvant effect could be ascribed primarily to the TMC polymer itself rather than to its formulation in nanoparticles. After ID injection of diphtheria toxoid (DT)loaded TMC nanoparticles or a solution of TMC and DT (TMC/DT mixture), mice developed 4-fold higher IgG titres compared to those induced by plain DT. These results indicate that in ID vaccination, antigen-loaded TMC nanoparticles are not superior to soluble TMC/antigen mixtures, in contrast with, e.g., intranasal vaccination $(16,17)$. This might be attributed to the fact that with ID injection, antigen and adjuvant are immediately delivered to an APC-rich environment, thereby making nanoparticles unnecessary.

Transcutaneous vaccination differs from ID vaccination in that the antigen first has to be transported into the skin. Only then can it be taken up by skin resident APCs and induce APC maturation. The natural function of the skin is to protect the body from the environment (18). This function is exerted by the upper part of the epidermis, the stratum corneum. Even though this part is only $15 \mu \mathrm{m}$ thick in human skin, it proves to be an excellent barrier. One way to breach this barrier is by using microneedles. The idea of using microneedles for transdermal drug delivery dates back to 1971 (19), but only in the 1990s the first microneedles were developed (20). Since then, their usage has increased, and many different microneedles have become available. Some devices are currently being tested in clinical trials (21), and several others are in pre-clinical development (22-24). The use of microneedles for vaccine delivery can be based on different principles: hollow microneedles can be used for injection of liquids; solid microneedles can either be coated with the antigen of interest or used for perforation of the skin prior to vaccine application. The main advantage of microneedles is that they are long enough to penetrate the stratum corneum, but short enough to avoid pain and major discomfort $(25,26)$. During the past few years, we have been studying solid microneedle arrays to pre-treat the skin, followed by vaccine application. In previous studies, our group showed that microneedle pre-treatment significantly increased antibody titres in transcutaneous vaccination studies with DT $(27,28)$.

In this study, we will focus on the transport of DTloaded TMC nanoparticles and TMC/DT mixtures into the skin by applying them as liquid formulations in combination with two types of solid microneedles. Immunisation studies in mice were employed to compare the antibody responses elicited by microneedle-based delivery to ID delivery. To visualise the transport of soluble and particulate TMC into the skin, the adjuvant was fluorescently labelled, and confocal microscopy studies were performed.

\section{MATERIALS AND METHODS}

\section{Materials}

Chitosan (MW $120 \mathrm{kDa}$ ) with a degree of deacetylation of 92\% was obtained from Primex (Alversham, Norway). Cholera toxin (CT), pentasodium tripolyphosphate (TPP), $\mathrm{N}$-(2-hydroxyethyl) piperazine-N'-(2-ethanesulphonic acid) (HEPES) and rhodamine B isothiocyanate were obtained from Sigma Aldrich (Zwijndrecht, The Netherlands). Diphtheria toxin (DTa 79/1) and DT (batch 98/40, protein content $12.6 \mathrm{mg} / \mathrm{ml}$ by BCA assay, $1 \mu \mathrm{g}$ equal to approximately $0.3 \mathrm{Lf}$ ) were a kind gift from the Netherlands Vaccine Institute (NVI, Bilthoven, The Netherlands). Horseradish peroxidase (HRP) conjugated goat antimouse IgG ( $\gamma$ chain specific), IgGl ( $\gamma 1$ chain specific) and IgG2a ( $\gamma 2$ a chain specific) were purchased from Southern Biotech (Birmingham, USA). Chromogen 3, 3', 5, 5'tetramethylbenzidine (TMB) and the substrate buffer were purchased from Invitrogen (Breda, The Netherlands). Nimatek $^{\circledR}(100 \mathrm{mg} / \mathrm{ml}$ Ketamine, Eurovet Animal Health B.V., Bladel, The Netherlands), Oculentum Simplex (Farmachemie, Haarlem, The Netherlands), Rompun ${ }^{\circledR}$ (20 mg/ml Xylazine, Bayer B.V., Mijdrecht, The Netherlands) and the injection fluid $(0.9 \% \mathrm{NaCl})$ were obtained from a local pharmacy. All other chemicals were of analytical grade.

\section{Animals}

Female BALB/c mice (H2d), 8 weeks old at the start of the vaccination study and male hairless (skh-1) mice, 7-9 weeks old were purchased from Charles River (Maastricht, The Netherlands) and maintained under standardised conditions in the animal facility of the Leiden/Amsterdam Centre for Drug Research, Leiden University. The study was carried out under the guidelines compiled by the Animal Ethic Committee of the Netherlands.

\section{Vaccine Formulations}

TMC with a degree of quarternisation of $15 \%$ was synthesised from chitosan in a one-step methylation reaction as described previously (15). The LPS content of 
TMC was found to be below the detection limit $(<0.1 \mathrm{ng} / \mathrm{ml}$ for $1 \mathrm{mg} / \mathrm{ml} \mathrm{TMC})$ when tested on TLR4 transfected HEK cells (data not shown). For confocal microscopy studies, the TMC was labelled at the amine group with rhodamine B isothiocyanate. TMC was dissolved in a $0.1 \mathrm{M}$ carbonate buffer $\mathrm{pH} \mathrm{9}$, and rhodamine $\mathrm{B}$ isothiocyanate was added in a TMC: rhodamine ratio of 15:1. After subsequent dialysis in $1 \% \mathrm{NaCl}$ and water until no rhodamine could be detected in the dialysis solution (measured by fluorescence), the TMC-rhodamine solution was freeze dried.

TMC nanoparticles were prepared by ionic complexation with TPP. A TMG:TPP $(\mathrm{w} / \mathrm{w})$ ratio of $6.7: 1$ was used as described before (15). Briefly, for the preparation of DT-loaded nanoparticles, $1 \mathrm{mg}$ of DT was added to a $5 \mathrm{mM}$ HEPES pH 7 solution containing $10 \mathrm{mg}$ TMC. After addition of TPP and $1 \mathrm{~h}$ of stirring, the nanoparticle suspension was centrifuged for $15 \mathrm{~min}$ at $10,000 \mathrm{~g}$ on a glycerol bed. The pellet was resuspended in $10 \mathrm{mM}$ phosphate buffer adjusted to $\mathrm{pH}$ 7.4. The size of the nanoparticles was determined by dynamic light scattering (DLS), and the zetapotential was determined by laser Doppler velocimetry using a Zetasizer ${ }^{\circledR}$ Nano ZS (Malvern Instruments, UK). The amount of DT in the particles was measured with a micro-BCA protein assay (Pierce, Rockford, IL, USA). TMC/DT mixtures were prepared by mixing them in a 2.5:1 $(\mathrm{w} / \mathrm{w})$ ratio. To further potentiate the immune response in some cases, CT was added to the formulations in a DT:CT ratio of $1: 1(\mathrm{w} / \mathrm{w})$ just before usage. Finally, DT adsorbed to aluminium phosphate (Adju-Phos ${ }^{\circledR}$; Brenntag Biosector, Denmark) (DT-alum) was prepared in a DT:alum ratio of 1:30 as previously described, and the adsorption was between 70 and $80 \%(29)$.

\section{Microneedles}

Two types of microneedle arrays were used. Assembled metal microneedle arrays with a length of $300 \mu \mathrm{m}$ (300A) were manufactured from commercially available $30 \mathrm{G}$ hypodermic needles (30). 30G needles have a diameter of $300 \mu \mathrm{m}$ at the base and a tapered shaft of approximately $1.2 \mathrm{~mm}$, thereby forming an angle of approximately $15^{\circ}$. These microneedles were positioned in a $4 \times 4$ pattern in a polymer mould (diameter $5 \mathrm{~mm}$ ) with a pitch of $1.25 \mathrm{~mm}$. The second type of array consists entirely of stainless steel, and the microneedles were prepared by electrical discharge machining (300ED). Similar as the 300A, the 300ED microneedles are $300 \mu \mathrm{m}$ long and are positioned in a $4 \times 4$ pattern with a pitch of $1.25 \mathrm{~mm}$. They differ from the $300 \mathrm{~A}$ microneedles in shape, as can be observed in Fig. 1. They have a square base of $250 \times 250 \mu \mathrm{m}$, and the tip of the microneedles is less sharp than that of the
300A microneedles. The shape of the tip is defined by a diagonal plane which runs from the top of one side of the square pillar to the opposed bottom, in this way forming an angle of approximately $40^{\circ}$ relative to the bottom surface. An electrical applicator was used to apply the microneedles with a speed of $3 \mathrm{~m} / \mathrm{s}$ to ensure reproducible piercing of the skin (25).

\section{Immunisation Studies}

The immunogenicity of the DT-loaded TMC nanoparticles and TMC/DT mixtures was assessed in an immunisation study in mice using the two types of microneedle arrays. The microneedle arrays were applied on the abdominal skin under anaesthesia (by intraperitoneal injection of $150 \mathrm{mg} / \mathrm{kg}$ Ketamine and $10 \mathrm{mg} / \mathrm{kg}$ Xylazine). The microneedles were applied in two ways: either before or after application of the formulations. In both cases, $70 \mu \mathrm{l}$ of the formulations containing $100 \mu \mathrm{g}$ DT were applied on the skin for $1 \mathrm{~h}$ $\left(\sim 2 \mathrm{~cm}^{2}\right.$ area restricted by a metal ring). After the application, the skin was washed with lukewarm water to remove the remaining amount of formulation. Groups of 8 mice were vaccinated thrice with a three-week interval. To circumvent the skin barrier, the formulations ( $5 \mu \mathrm{g}$ $\mathrm{DT} / 30 \mu \mathrm{L}$ formulation) were also injected ID with a Hamilton syringe equipped with a $30 \mathrm{G}$ needle as described before (15). As a positive control, DT-alum $(5 \mu \mathrm{g}$ DT and $150 \mu \mathrm{g}$ alum/100 $\mu \mathrm{L}$ ) was injected subcutaneously $(\mathrm{SC})$. In some groups $\mathrm{CT}$ was used as an additional adjuvant: $10 \mu \mathrm{g}$ per mouse for ID $100 \mu \mathrm{g}$ for the microneedle groups. One day before each immunisation blood samples were collected from the tail vein. Three weeks after the last vaccination the mice were sacrificed. Just before euthanasia total blood was collected from the femoral artery. Blood samples were collected in MiniCollect ${ }^{\circledR}$ tubes (Greiner Bio-one, Alphen a/d Rijn, The Netherlands) until clot formation and centrifuged $10 \mathrm{~min}$ at $10,000 \mathrm{~g}$ to obtain cell-free sera. The sera were stored at $-80^{\circ} \mathrm{C}$ until further use.

\section{Detection of Serum IgG, IgGI and IgG2a}

DT-specific antibodies (IgG, IgG1 \& IgG2a) in the sera were determined by sandwich ELISA as described previously (27). Briefly, plates were coated overnight with $140 \mathrm{ng}$ DT. After blocking, two-fold serial dilutions of sera from individual mice were applied to the plates. HRP-conjugated antibodies against IgG were added and detected by TMB. Antibody titres were expressed as the reciprocal of the sample dilution that corresponds to half of the maximum absorbance at $450 \mathrm{~nm}$ of a complete s-shaped absorbancelog dilution curve. 

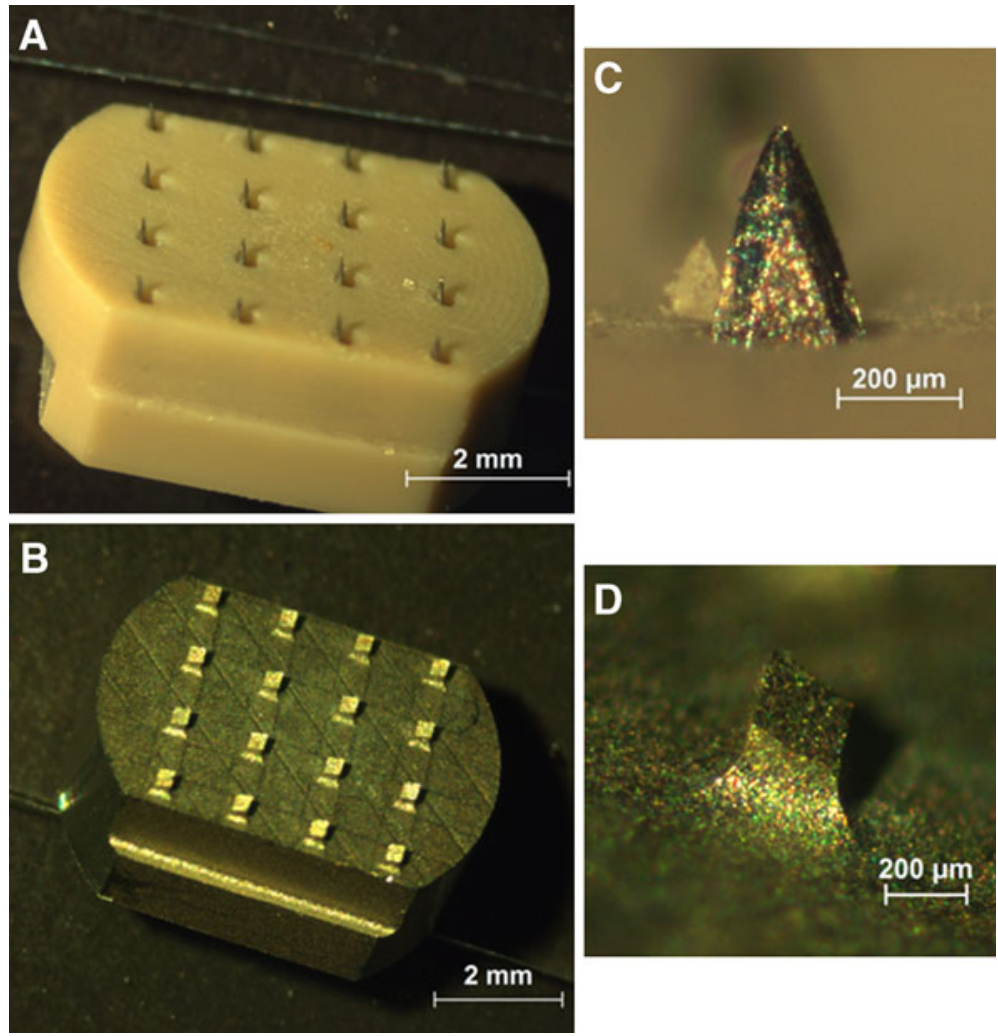

Fig. I The two types of microneedles used in this study. A: Array of 300A microneedles, manufactured from commercially available 30G needles. B: Array of 300ED microneedles, made of stainless steel. Both arrays contain sixteen microneedles with a length of $300 \mu \mathrm{m}$. In figure C and D higher magnification images of a single 300A microneedle $(\mathbf{C})$ and a 300ED microneedle (D) are shown.

\section{Vero Cell Test}

The levels of diphtheria toxin-neutralising antibodies in mouse sera were assessed by a Vero cell test as described previously (31). Control samples included were reference anti-serum and untreated cells. The plates were incubated at $37^{\circ} \mathrm{C}$ in $5 \% \mathrm{CO}_{2}$ for 6 days, and afterwards the presence of living cells was verified by light microscopy. The neutralising antibody titres were obtained from the serum dilution factor that still resulted in living cells.

\section{Analysis of In Vivo Transport into the Skin by Confocal Microscopy}

To visualise the transport into the skin of TMC nanoparticles compared to a TMC solution, hairless (skh-1) mice were treated with empty rhodaminelabelled TMC nanoparticles or a TMG solution. In this case, the 300A microneedles were used, and the mice were pre-treated with the microneedles before occlusive application of the formulations. An equal concentration of rhodamine-labelled TMC was used in both formulations, as determined by fluorescence spectroscopy
(FS920 fluorimeter, Edinburgh Instruments, Campus Livingston, UK). After $1 \mathrm{~h}$ of application, the formulations were removed with a cotton bud. To visualise the distribution of the nanoparticles and solution in the skin, the formulations were also injected ID. After the mice were euthanised, the treated skin area was removed, immediately mounted on a sample holder and visualised with a confocal laser scanning microscope. Images were taken every $10 \mu \mathrm{m}$, over a total depth of $300 \mu \mathrm{m}$. Images were processed using a Bio-Rad Radiance 2100 confocal laser scanning system equipped with a Nikon Eclipse TE2000-U inverted microscope and either a $4 \mathrm{X}$ plan fluor or a $10 \mathrm{X}$ plan air objective (Nikon, Japan). The images were captured using a helium neon laser at $543 \mathrm{~nm}$, with a 570 long pass emission filter. Image acquisition was controlled using the Laser Sharp 2000 software (Bio-Rad, Hercules, USA). The amount of TMC in the conduits was estimated from the images using Image J (National institute of health, USA). The distribution area of TMC was calculated by the number of pixels in the specified area containing a level of fluorescence above the threshold value. Threshold settings were 20 AU (lower 
threshold) and 255 (upper threshold). A fluorescent intensity below 20 AU was regarded as background fluorescence.

\section{Statistical Analysis}

Statistical analysis was performed with Prism 5 for Windows (Graphpad, San Diego, USA). Data are presented as mean \pm SD for the immunisation studies and as mean \pm SEM for the confocal results. Statistical significance was determined by a two-way analysis of variance (ANOVA) with a Bonferroni post-test. The results of the Vero cell test were analysed by a Kruskal-Wallis test with a Dunn's multiple comparison post-test.

\section{RESULTS}

\section{Physicochemical Characteristics of the Formulations}

DT-loaded TMC nanoparticles were prepared with a mean size of $211 \pm 4 \mathrm{~nm}$ and a PDI of $0.15 \pm 0.01$. They were positively charged (zetapotential $12.9 \pm 0.8 \mathrm{mV}$ in $10 \mathrm{mM}$ sodium phosphate $\mathrm{pH} 7.4$ ), and the loading efficiency of DT in the nanoparticles was about $70 \%$. In the TMC/DT mixtures, $\sim 50 \%$ of the DT was adsorbed to the $\mathrm{TMC}$, which is likely due to the fact that TMC and DT carry opposite charges at $\mathrm{pH} 7.4$ (15). As reported previously, the release of the antigen from the nanoparticles in PBS was characterised by an immediate burst without any further release over the next 9 days (15).

\section{Combining Microneedles and Nanoparticles for Transcutaneous Vaccination}

In Fig. 2A, the anti-DT IgG titres after application of the 300A microneedles are shown. By applying a solution of DT on microneedle pre-treated skin, an immune response was initiated, with IgG titres 100-fold higher compared to application of DT on intact skin (27). Still, these titres were significantly lower compared to those obtained after SC application of DT-alum, the positive control. Formulating DT into TMG nanoparticles did not further increase the immune response. In contrast, when a mixture of TMC and DT solutions was applied on microneedle-pre-treated skin, the IgG titres after the second boost were 8-fold higher compared to application of a solution of DT $(p<0.001)$ and comparable to those elicited by SC DT-alum. Similar results were obtained for the neutralising antibody titres (Fig. 2B): after the second boost with a TMC/DT mixture, a clear trend of enhanced titres compared to a solution of DT were observed, whereas nanoparticles did not enhance the titres. The titres after application of the TMC/DT mixture, were not significantly different from those elicited by SC DT-alum $(p=0.26)$.

It was thought that by applying the formulation before microneedle treatment, the microneedles might carry the formulation with them into the skin (Fig. 2A). This application method indeed induced higher $\operatorname{IgG}$ titres after the first boost $(p<0.01)$, but the $\operatorname{IgG}$ and neutralising antibody titres after the second boost did not differ significantly from those obtained after the original sequence of application, i.e. microneedle treatment prior to applying the nanoparticles. This indicates that both methods of microneedle application result in similar immunogenicity. Because the dose is more controlled when the formulations are applied after microneedle pre-treatment, it was decided to continue with this application method in the following studies.

To investigate the effect of the shape of the microneedle array, two different arrays were used: the 300A and the 300ED. Even though the microneedle arrays differ in shape and sharpness (Fig. 1), similar IgG and neutralising antibodies were observed after pre-treatment using either of the two arrays (Fig. 3).

To further potentiate the immunogenicity of the formulations, CT was added to the nanoparticles. Fig. 3A shows that addition of $\mathrm{CT}$, as compared to nanoparticles alone, significantly enhanced the IgG titres after the prime and two subsequent booster vaccinations $(p<0.001)$. The titres obtained after the second boost were comparable to those after SC DT-alum immunisation. The results of the neutralising antibody assay confirmed these results (Fig. 3B). Furthermore, CT not only had an effect on the total IgG titres, but also affected the $\operatorname{IgG1} / \mathrm{IgG} 2 \mathrm{a}$ ratio. After immunisation with DT and TMC, mainly IgG1 titres were induced (Fig. 3G), which is indicative of a Th2-biased response $(32,33)$. The addition of CT to the nanoparticle formulations increased the IgG2a titres significantly $(p<$ 0.01 ), pointing to a more Thl-skewed response.

\section{ID Immunisation with TMC-Based Formulations}

In transcutaneous immunisation, the transport of topically applied vaccine into the skin could be an important barrier to delivery of the vaccine to the APCs in the skin. To eliminate this transport factor, the formulations were injected ID. In Fig. 4 the antibody titres are shown after ID injection of mice with a DT solution, a TMC/DT mixture and DT-loaded TMC nanoparticles with and without CT. In line with a previous study (15), the TMC nanoparticles resulted in significantly higher IgG titres compared to those elicited after ID injection of a DT solution (Fig. 4A), and higher neutralising antibody titres were also observed (Fig. 4B). DT-loaded TMC nanoparticles and TMC/DT mixture induced comparable antibody titres, and the levels were not 

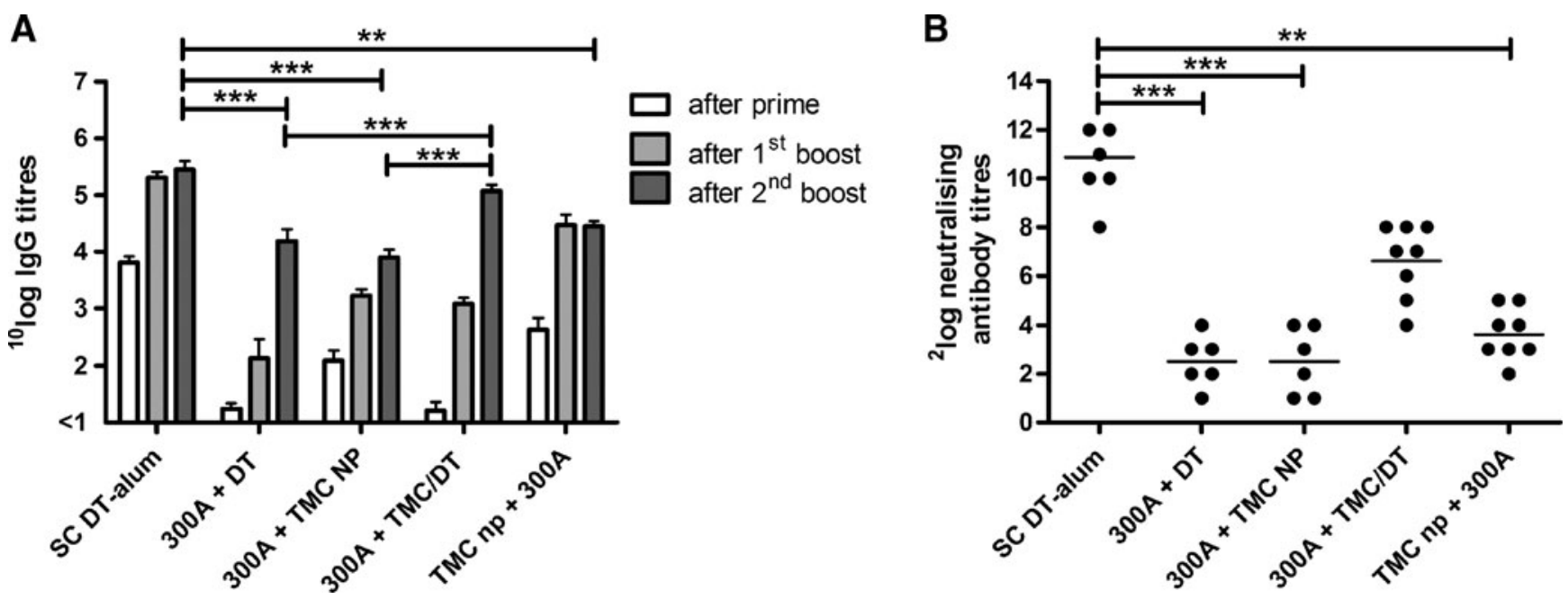

Fig. $2 \lg G(A)$ and neutralising antibody (B) titres obtained after piercing with 300A microneedles followed by application of a DT solution, a TMC/DT mixture or DT-loaded TMC nanoparticles (TMC NP) as compared to SC DT-alum. A: IgG titres after prime and two booster vaccinations. Mean and SD of 8 mice. B: Neutralising antibody titres after second boost. Data are expressed as the highest dilution that was still capable of protecting the Vero cells against challenge with diphtheria toxin. $* * * 0.01$, ***** $p<0.001$.

significantly different from those obtained after SC immunisation with DT-alum (Fig. 4A,B). When CT was added to the nanoparticle formulation, it accelerated and potentiated the immune response (Fig. 4A). Higher IgG titres were obtained compared to the SC DT-alum control after the prime and first boost $(p<0.01)$. Furthermore, after the second boost, the addition of CT induced significantly higher neutralising antibody titres $(p<0.05)$ compared to plain DT (Fig. 4B). After ID immunisation with all formulations the main IgG subtype produced was IgG1, but the DT-loaded TMC nanoparticles enhanced the production of $\operatorname{IgG} 2 \mathrm{a}$ antibodies $(p<0.01)$. For the CT-containing formulation, the IgG2a response was most pronounced $(p<0.001)$.

\section{Visualisation of TMC Transport into Skin}

Fig. 5 shows representative images of the transport of fluorescently labelled TMC nanoparticles and a TMC solution into the microneedle conduits. With confocal microscopy, easily all conduits could be visualised (Fig. 5A), indicating that piercing with the microneedle arrays was successful. In the conduits, fluorescence was present in the deeper layers of the skin, until a depth of approximately $150 \mu \mathrm{m}$ (Fig. 5B). This image also illustrates the shape of the conduits. Higher magnification images of single conduits were also made (see Fig. S1, Supplementary Material). The images show that at the skin surface, adjacent to the conduits, fluorescence was observed in the furrows. Deeper in the skin, the dye was solely present in the conduits. The fraction of the TMC-rhodamine that will be transported into the skin through the conduits is small. To compare the transport into the skin of both formulations, the area containing measurable dye fluorescence and the fluorescent intensity were calculated from the images. In Fig. 6, the area containing TMC-rhodamine is plotted against the skin depth. The maximum area of TMC-rhodamine (solution and nanoparticles) was not found at the surface, but at a depth of 20-30 $\mu \mathrm{m}$ in the skin. When TMC-rhodamine was applied in solution, it was distributed over a larger area in the skin compared to application of TMC-rhodamine nanoparticles. The distribution areas differ significantly at a depth of $30-70 \mu \mathrm{m}(p<0.05)$, indicating a broader distribution of the TMC-rhodamine solution. No difference in the penetration depth was observed between the TMCrhodamine solution and TMC-rhodamine nanoparticles.

Images were also taken after ID injection of rhodaminelabelled TMC (Fig. 7). In this case, the fluorescence could be observed over a depth of $200 \mu \mathrm{m}$. It is evident that the TMC is distributed over a much larger area when applied as a solution (Fig. 7A) than in nanoparticulate form (Fig. 7B).

\section{DISCUSSION}

A combination of microneedles with adjuvants implements the two main requirements for effective minimally invasive transcutaneous immunisation: increased transport across the stratum corneum and induction of a protective immune response. Both the microneedles and the TMC-based formulations have already proven their effectiveness in previous in vivo studies $(15,27,28)$. Moreover, because of the positive charge of the TMC, it easily forms complexes with the negatively charged antigen DT and can induce maturation of DCs in vitro (15). The potent adjuvant effect of TMC in the skin is clearly shown after ID injection. Both the TMC/DT mixture and the TMC 

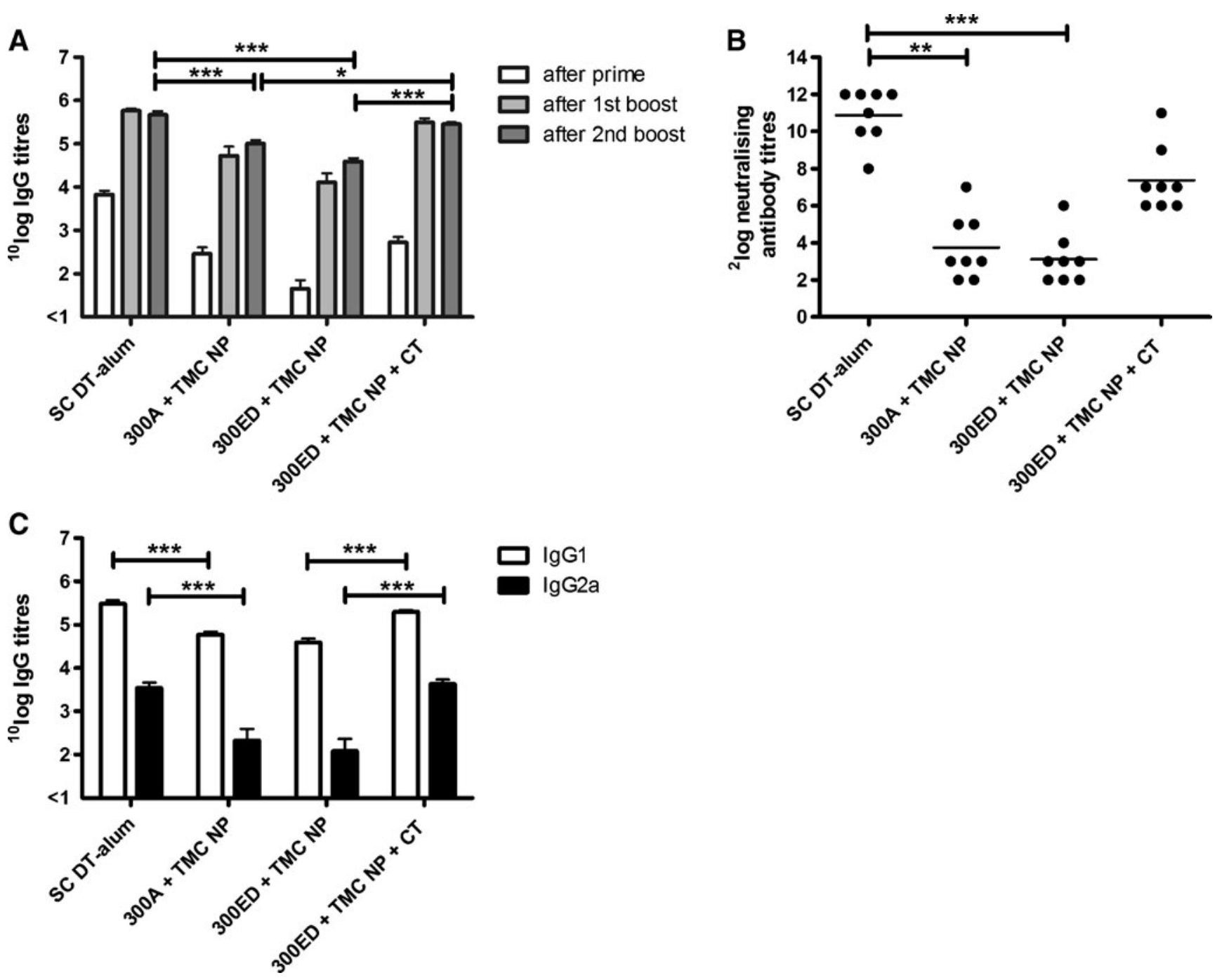

Fig. 3 Effects of microneedle array type and co-administration of CTon the immunogenicity of the DT-loaded TMC nanoparticles (TMC NP) after microneedle pre-treatment. A: $\lg G$ titres after prime and 2 booster vaccinations. B: Neutralising antibody titres after 2nd boost. Data are expressed as the highest dilution that was still capable of protecting the Vero cells against challenge with diphtheria toxin. $\mathbf{C}$ : IgGI and lgG2a titres after 2nd boost. A/C: Mean and SD of 8 mice. B: Individual values and geometric mean of 8 mice are shown. $*<<0.05$, *** $p<0.01$, **** $p<0.001$.

nanoparticles induced an equally strong immune response, eliciting similar titres as after SC DT-alum administration.

Besides ID immunisation, microneedle-based application of a TMC/DT mixture also increased the antibody titres compared to the application of a DT solution. However, topically applied DT-loaded TMC nanoparticles were not able to enhance the immune response. The method of microneedle application or the type of microneedle array used could not improve the immunogenicity of the TMC nanoparticles. Similarly, as observed with the TMC nanoparticles, positively charged liposomes also failed to enhance the immune response against DT after microneedle pre-treatment (34). Even though nanoparticles are mentioned as a promising tool for transcutaneous vaccination (9), their usage so far is limited. Studies focussed on the transport of different types of nanoparticles across intact skin have shown that, in most cases, the nanoparticles remain in the stratum corneum or the hair follicles (35-37). The few groups that claim successful penetration of nanoparticles into the skin either lack an adequate explanation of the discrepancies found for the transport of nanoparticles differing in size and charge (38) or could not demonstrate whether the nanoparticles themselves or only the released dye penetrates the skin (39). Lipid-based vesicles, which are thought to penetrate the skin more easily, were shown to remain in the stratum corneum (40-42). From these studies, it can be concluded that, for successful delivery of nanoparticles into the skin, the stratum corneum barrier needs to be breached. Our group reported for the first time the in vitro visualisation of transport of commercially available 

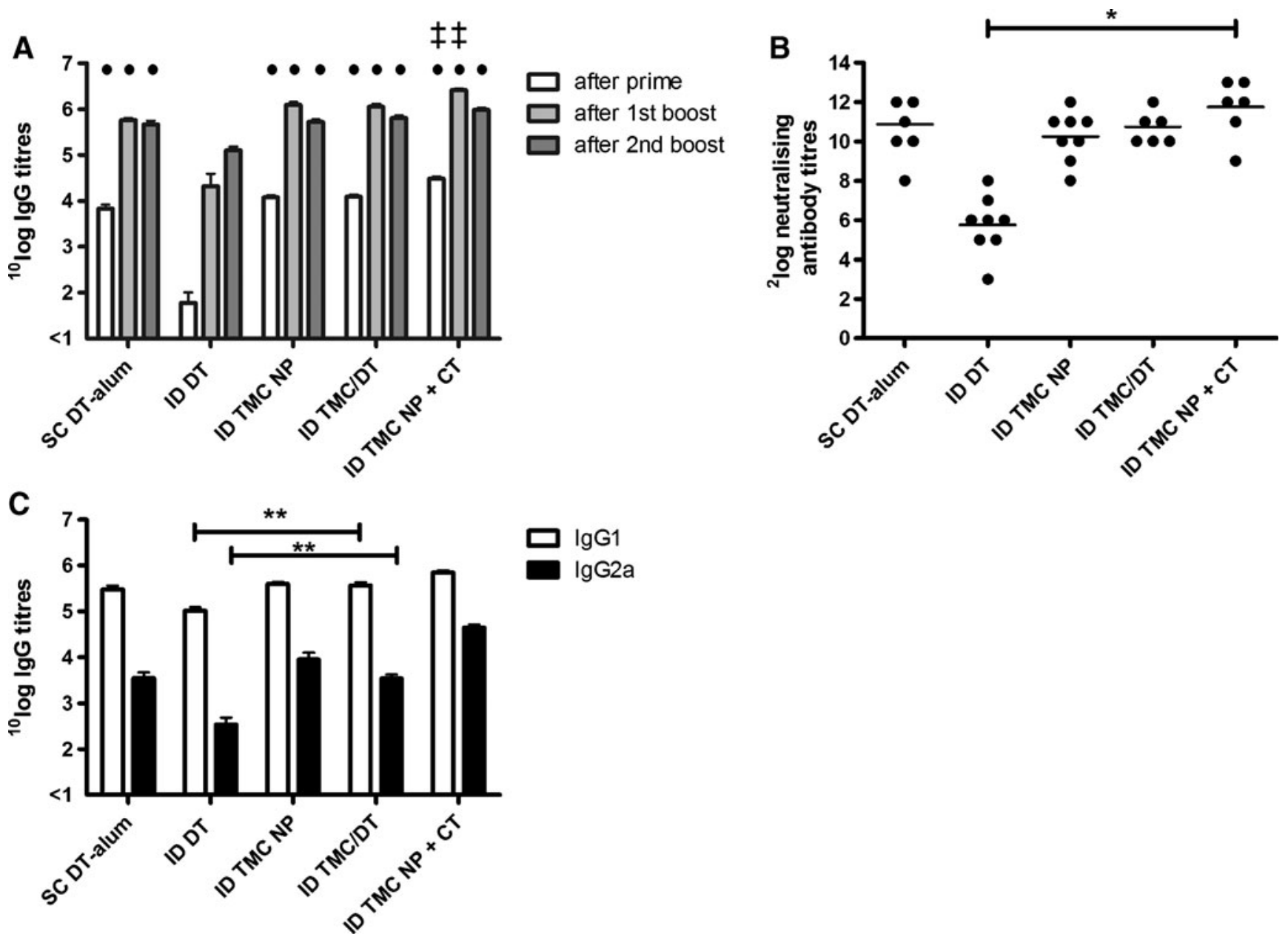

Fig. $4 \mathrm{lgG}(\mathrm{A})$ and neutralising antibody (B) titres after ID vaccination with the different formulations. A: $\lg G$ titres after prime and 2 booster vaccinations. B: Neutralising antibody titres after 2 nd boost. Data are expressed as the highest dilution that was still capable of protecting the Vero cells against challenge with diphtheria toxin. $\mathbf{C}$ : $\lg \mathrm{g} \mid$ and $\lg \mathrm{g} 2 \mathrm{a}$ titres after 2 nd boost. A/C: Mean and SD of 8 mice. B: Individual values and geometric mean of 8 mice are shown. - significantly higher compared to ID DT. $\ddagger$ significantly higher compared to SC DT-alum. $* p<0.05, * * * 0.01$.
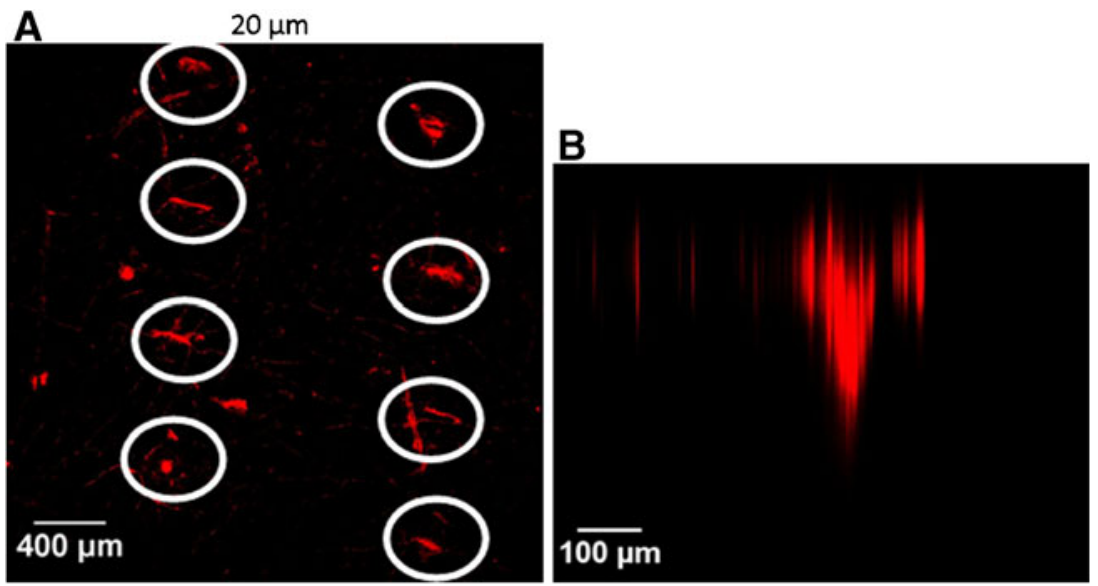

Fig. 5 Representative images of microneedle conduits in mouse skin. A: x,y image (parallel to skin surface) showing 8 conduits at the skin surface. B: $x, z$ image (perpendicular to the skin surface) showing penetration of TMC-rhodamine until a depth of approximately I50 $\mu \mathrm{m}$. 


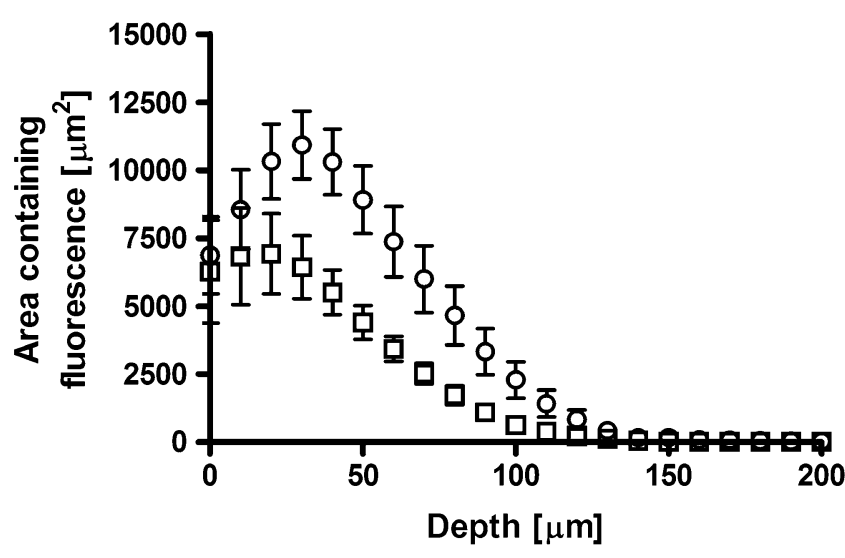

Fig. 6 Determination of the fluorescence in the skin after microneedle pre-treatment and application of either TMC-rhodamine nanoparticles or a TMC-rhodamine solution. Area containing fluorescence plotted against the skin depth. Mean and SEM of 3 mice.

polymeric nanoparticles with a size of $200 \mathrm{~nm}$ into human skin after pre-treatment with the 300A microneedles (30). The nanoparticles could be traced until a depth of approximately $250 \mu \mathrm{m}$. These results were confirmed by Coulman et al., who pre-treated the skin with $280-\mu \mathrm{m}-\mathrm{long}$ microneedles and showed that nanoparticles with a size of $138 \mathrm{~nm}$ were able to penetrate into the epidermis (43). To further investigate the transport of TMC nanoparticles and a TMC solution, visualisation studies were performed. We visualised ex vivo the transport of positively charged TMC nanoparticles into the skin. We showed that these nanoparticles could be transported through the microneedle conduits, though to a lower extent compared to the polymer in solution. The conduit area containing TMCrhodamine was larger for the solution than for the nanoparticles, indicating a broader distribution of the TMC solution. A possible reason for this is blockage of the conduits due to the electrostatic interactions between the positively charged nanoparticles and the negatively charged skin. Also, the presence of proteins may cause aggregation of the nanoparticles, making the transport of the nanoparticles through the conduits to the APCs an important limiting factor. It should be noted that by prolonging the application time of the formulations $(>1 \mathrm{~h})$, the transport might be boosted.

The addition of an additional adjuvant (CT) to the nanoparticles increased the $\mathrm{IgG}$ and neutralising antibody titres after microneedle pre-treatment, reaching similar IgG levels as after SG immunisation with DT-alum. It is worthwhile to mention that next to enhanced total antibody levels, addition of CT also induced substantially higher IgG2a titres and, hence, affected the IgG1/IgG2a ratio, both after ID and after transcutaneous application. This is in agreement with other transcutaneous immunisation studies performed with DT (28), the cross-reacting material (CRM197) of diphtheria toxin (44) and inactivated influenza virus (45). Elevated IgG2a titres could be beneficial in case of vaccination against viruses or intracellular bacteria, where a more Thl-biased response is required.

For DT, high IgG1 rather than IgG2a titres seem to correlate with protection $(28,46)$. In our studies, vaccination with DT mainly results in the production of $\mathrm{IgG} 1$ antibodies, indicating a Th2-biased, response as is usually reported for toxins (47). After transcutaneous immunisation, TMC strengthened this Th2 bias, in agreement with our in vitro studies on human monocyte derived DCs and $\mathrm{T}$ cells $(14,15)$. Contrarily, after ID administration, both TMC formulations enhanced significantly the production of $\operatorname{IgG} 1$, but even more that of IgG2a. This could be explained by the fact that after ID injection the formulations will reach the dermis, while with the microneedles also the epidermis is targeted. Previous studies in mice have shown that by immunising via the epidermis mainly a Th2-biased response is elicited (48-51). It is thought that

\section{Solution}

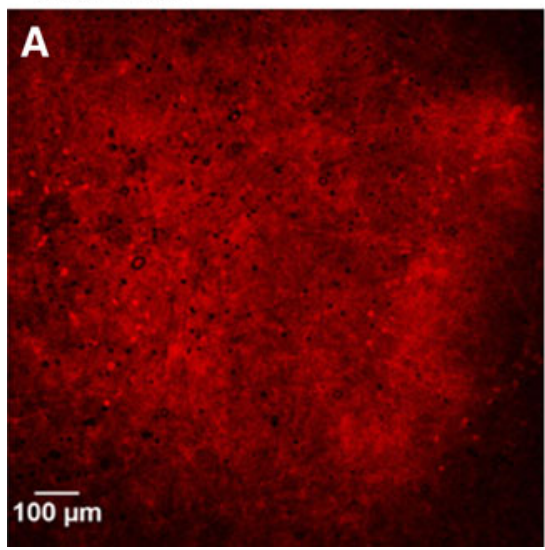

\section{Nanoparticles}

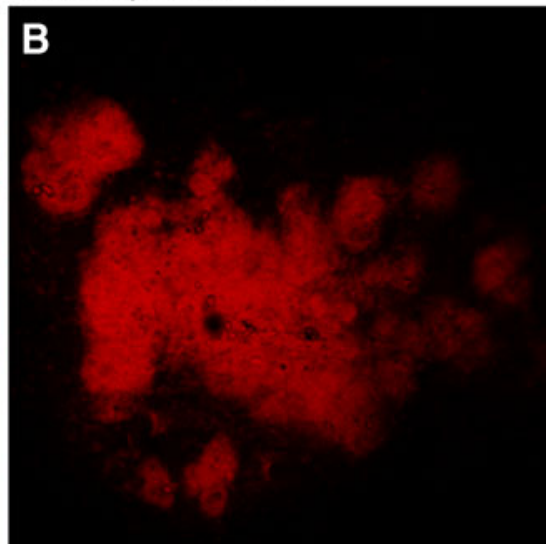

Fig. $7 X, y$ images (parallel to the skin surface) showing the distribution pattern in the dermis after ID injection of either a TMC-rhodamine solution (A) or TMC-rhodamine nanoparticles (B). 
in these cases the immune response is initiated mainly by epidermal LCs that take up the antigen and migrate to the lymph nodes (51). In addition, Klechevsky et al. showed that human LCs upon stimulation with CD40L efficiently induced the secretion of Th2 type cytokines by T cells (52). In the dermis of mice, two types of DCs are present: the classical dermal DCs and a recently discovered langerin ${ }^{+}$ DCs (53-55). This subtype differs from LCs and the classical dermal DGs by a low expression of CD11b and high expression of CD103. The exact role of these dermal

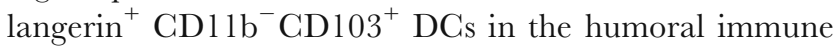
response is not clear yet, but the presence of different $\mathrm{DC}$ subtypes in the epidermis and dermis could explain the different immune response generated after transcutaneous and ID immunisation.

\section{CONCLUSION}

For successful transcutaneous immunisation, both the transport into the skin and the activation of the APCs are important. This can be achieved by the combination of microneedles and an adjuvant. TMC offers great promise as an adjuvant for transcutaneous immunisation, but not when formulated in nanoparticles. Nanoparticles, which are much smaller, might be more suitable to use in combination with microneedle arrays. Moreover, as this study showed that a mixture of TMC and DT is able to increase the immunogenicity, conjugation between the polymer and the antigen could be a better option to further potentiate the immune response (56), also via the transcutaneous route.

\section{ACKNOWLEDGEMENTS}

This research was performed under the framework of TI Pharma project number D5-106-1, Vaccine delivery: alternatives for conventional multiple injection vaccines. The authors thank Bram Slütter for his helpful suggestions.

Open Access This article is distributed under the terms of the Creative Commons Attribution Noncommercial License which permits any noncommercial use, distribution, and reproduction in any medium, provided the original author(s) and source are credited.

\section{REFERENCES}

1. Mikszta JA, Laurent PE. Cutaneous delivery of prophylactic and therapeutic vaccines: historical perspective and future outlook. Exp Rev Vaccines. 2008;7:1329-39.

2. Ipp M, Parkin PG, Lear N, Goldbach M, Taddio A. Order of vaccine injection and infant pain response. Arch Pediat Adol Med. 2009;163:469-72.
3. Immunization safety. www.who.int/immunization_safety/safe_ injections/en/.

4. Raz E, Carson DA, Parker SE, Parr TB, Abai AM, Aichinger G, et al. Intradermal gene immunization-The possible role of DNA uptake in the induction of cellular-immunity to viruses. Proc Natl Acad Sci U S A. 1994;91:9519-23.

5. Bos JD, Kapsenberg ML. The skin immune-system-progress in cutaneous biology. Immunol Today. 1993;14:75-8.

6. Kupper TS, Fuhlbrigge RC. Immune surveillance in the skin: mechanisms and clinical consequences. Nat Rev Immunol. 2004;4:211-22.

7. Belshe RB, Newman FK, Wilkins K, Graham IL, Babusis E, Ewell $\mathrm{M}$, et al. Comparative immunogenicity of trivalent influenza vaccine administered by intradermal or intramuscular route in healthy adults. Vaccine. 2007;25:6755-63.

8. Holland D, Booy R, De Looze F, Eizenberg P, McDonald J, Karrasch J, et al. Intradermal influenza vaccine administered using a new microinjection system produces superior immunogenicity in elderly adults: a randomized controlled trial. J Infect Dis. 2008;198:650-8.

9. Combadiere B, Mahe B. Particle-based vaccines for transcutaneous vaccination. Comp Immunol Microb. 2008;31:293-315.

10. Wilson-Welder JH, Torres MP, Kipper MJ, Mallapragada SK, Wannemuehler MJ, Narasimhan B. Vaccine adjuvants: current challenges and future approaches. J Pharm Sci. 2009;98:1278316.

11. Vogt A, Combadiere B, Hadam S, Stieler KM, Lademann J, Schaefer $\mathrm{H}$, et al. $40 \mathrm{~nm}$, but not 750 or 1, $500 \mathrm{~nm}$, nanoparticles enter epidermal CDla+ cells after transcutaneous application on human skin. J Invest Dermatol. 2006;126:1316-22.

12. Amidi M, Pellikaan HC, Hirschberg H, de Boerd AH, Crommelin DJA, Hennink WE, et al. Diphtheria toxoid-containing microparticulate powder formulations for pulmonary vaccination: preparation, characterization and evaluation in guinea pigs. Vaccine. 2007;25:6818-29.

13. Hagenaars N, Mastrobattista E, Verheul R, Mooren I, Glansbeek $\mathrm{H}$, Heldens J, et al. Physicochemical and Immunological Characterization of $\mathrm{N}, \mathrm{N}, \mathrm{N}$-Trimethyl chitosan-coated whole inactivated influenza virus vaccine for intranasal administration. Pharm Res. 2009;26:1353-64.

14. Slutter B, Plapied L, Fievez V, Sande MA, des Rieux A, Schneider Y-J, et al. Mechanistic study of the adjuvant effect of biodegradable nanoparticles in mucosal vaccination. J Control Release. 2009;138:113-21.

15. Bal SM, Slütter B, van Riet E, Kruithof AC, Ding Z, Kersten GFA, et al. Efficient induction of immune responses through intradermal vaccination with $\mathrm{N}$-trimethyl chitosan containing antigen formulations. J Control Release. 2010;142:374-83.

16. Amidi M, Romeijn SG, Verhoef JC, Junginger HE, Bungener L, Huckriede A, et al. N-Trimethyl chitosan (TMC) nanoparticles loaded with influenza subunit antigen for intranasal vaccination: biological properties and immunogenicity in a mouse model. Vaccine. 2007;25:144-53.

17. Boonyo W, Junginger HE, Waranuch N, Polnok A, Pitaksuteepong T. Chitosan and trimethyl chitosan chloride (TMC) as adjuvants for inducing immune responses to ovalbumin in mice following nasal administration. J Control Release. 2007;121:168-75.

18. Elias PM. Stratum corneum defensive functions: an integrated view. J Invest Dermatol. 2005;125:183-200.

19. Gerstel MS, Place VA. Drug delivery device, US, 1976.

20. Henry S, McAllister DV, Allen MG, Prausnitz MR. Microfabricated microneedles: a novel approach to transdermal drug delivery. J Pharm Sci. 1998;87:922-5.

21. Van Damme P, Oosterhuis-Kafeja F, Van der Wielen M, Almagor Y, Sharon O, Levin Y. Safety and efficacy of a novel 
microneedle device for dose sparing intradermal influenza vaccination in healthy adults. Vaccine. 2009;27:454-9.

22. Koutsonanos DG, del Pilar Martin M, Zarnitsyn VG, Sullivan SP, Compans RW, Prausnitz MR, et al. Transdermal influenza immunization with vaccine-coated microneedle arrays. PLoS One. 2009;4:e4773.

23. Widera G, Johnson J, Kim L, Libiran L, Nyam K, Daddona PE, et al. Effect of delivery parameters on immunization to ovalbumin following intracutaneous administration by a coated microneedle array patch system. Vaccine. 2006;24:1653-64.

24. Matriano JA, Cormier M, Johnson J, Young WA, Buttery M, Nyam K, et al. Macroflux (R) microprojection array patch technology: a new and efficient approach for intracutaneous immunization. Pharm Res. 2002;19:63-70.

25. Bal SM, Caussin J, Pavel S, Bouwstra JA. In vivo assessment of safety of microneedle arrays in human skin. Eur J Pharm Sci. 2008;35:193-202.

26. Gill HS, Denson DD, Burris BA, Prausnitz MR. Effect of microneedle design on pain in human volunteers. Clin J Pain. 2008;24:585-94.

27. Ding Z, Verbaan FJ, Bivas-Benita M, Bungener L, Huckriede A, van den Berg DJ, et al. Microneedle arrays for the transcutaneous immunization of diphtheria and influenza in BALB/c mice. J Control Release. 2009;136:71-8.

28. Ding Z, Van Riet E, Romeijn S, Kersten GFA, Jiskoot W, Bouwstra JA. Immune modulation by adjuvants combined with diphtheria toxoid administered topically in BALB/c Mice after microneedle array pretreatment. Pharm Res. 2009;26:1635-43.

29. Metz B, Jiskoot W, Hennink WE, Crommelin DJA, Kersten GFA. Physicochemical and immunochemical techniques predict the quality of diphtheria toxoid vaccines. Vaccine. 2003;22:156-67.

30. Verbaan FJ, Bal SM, van den Berg DJ, Dijksman JA, van Hecke $\mathrm{M}$, Verpoorten $\mathrm{H}$, et al. Improved piercing of microneedle arrays in dermatomed human skin by an impact insertion method. J Control Release. 2008;128:80-8.

31. Miyamura K, Tajiri E, Ito A, Murata R, Kono R. Micro cellculture method for determination of dihptheria-toxin and antitoxin and antitoxin titers using vero cells 2. Comparison with rabbit skin method and practical application for seroepidemiological studies. J Biol Stand. 1974;2:203-9.

32. Collins JT, Dunnick WA. Germline transcripts of the murine immunoglobulin gamma 2a gene: structure and induction by IFNgamma. Int Immunol. 1993;5:885-91.

33. Severinson E, Fernandez C, Stavnezer J. Induction of germ-line immunoglobulin heavy chain transcripts by mitogens and interleukins prior to switch recombination. Eur J Immunol. 1990;20:1079-84.

34. Ding Z, Bal SM, Hahn T, Romeijn S, Kersten GFA, Jiskoot W, et al. Transcutaneous immunization studies in mice using diphtheria toxoid-loaded vesicle formulations and a microneedle array. Pharm Res. In Press.

35. Alvarez-Román R, Naik A, Kalia YN, Guy RH, Fessi H. Skin penetration and distribution of polymeric nanoparticles. J Control Release. 2004;99:53-62.

36. Baroli B, Ennas MG, Loffredo F, Isola M, Pinna R, LopezQuintela MA. Penetration of metallic nanoparticles in human fullthickness skin. J Invest Dermatol. 2007;127:1701-12.

37. Lademann J, Richter H, Teichmann A, Otberg N, Blume-Peytavi U, Luengo J, et al. Nanoparticles-An efficient carrier for drug delivery into the hair follicles. Eur J Pharm Biopharm. 2007;66:159-64.

38. Kohli AK, Alpar HO. Potential use of nanoparticles for transcutaneous vaccine delivery: effect of particle size and charge. Int J Pharm. 2004;275:13-7.

39. Sheihet L, Chandra P, Batheja P, Devore D, Kohn J, Michniak B. Tyrosine-derived nanospheres for enhanced topical skin penetration. Int J Pharm. 2008;350:312-9.
40. van den Bergh BAI, Vroom J, Gerritsen H, Junginger HE, Bouwstra JA. Interactions of elastic and rigid vesicles with human skin in vitro: electron microscopy and two-photon excitation microscopy. BBA-Biomembranes. 1999;1461:15573.

41. Honeywell-Nguyen PL, Groenink HWW, de Graaff AM, Bouwstra JA. The in vivo transport of elastic vesicles into human skin: effects of occlusion, volume and duration of application. J Control Release. 2003;90:243-55.

42. Honeywell-Nguyen PL, Gooris GS, Bouwstra JA. Quantitative assessment of the transport of elastic and rigid vesicle components and a model drug from these vesicle formulations into human skin in vivo. J Invest Dermatol. 2004;123:902-10.

43. Coulman SA, Anstey A, Gateley C, Morrissey A, McLoughlin P, Allender C, et al. Microneedle mediated delivery of nanoparticles into human skin. Int J Pharm. 2009;366:190-200.

44. Stickings P, Peyre M, Coombes L, Muller S, Rappuoli R, Del Giudice $\mathrm{G}$, et al. Transcutaneous immunization with crossreacting material CRM197 of diphtheria toxin boosts functional antibody levels in mice primed parenterally with adsorbed diphtheria toxoid vaccine? Infect Immun. 2008;76:1766-73.

45. Skountzou I, Quan F-S, Jacob J, Compans RW, Kang S-M. Transcutaneous immunization with inactivated influenza virus induces protective immune responses. Vaccine. 2006;24: 6110-9.

46. McNeela EA, Jabbal-Gill I, Illum L, Pizza M, Rappuoli R, Podda $\mathrm{A}$, et al. Intranasal immunization with genetically detoxified diphtheria toxin induces $\mathrm{T}$ cell responses in humans: enhancement of Th2 responses and toxin-neutralizing antibodies by formulation with chitosan. Vaccine. 2004;22:909-14.

47. Zinkernagel RM. On natural and artificial vaccinations. Annu Rev Immunol. 2003;21:515-46.

48. Kondo H, Ichikawa Y, Imokawa G. Percutaneous sensitization with allergens through barrier-disrupted skin elicits a Th2-dominant cytokine response. Eur J Immunol. 1998;28: 769-79

49. Wang LF, Lin JY, Hsieh KH, Lin RH. Epicutaneous exposure of protein antigen induces a predominant Th2-like response with high IgE production in mice. J Immunol. 1996;156:4079-82.

50. Strid J, Callard R, Strobel S. Epicutaneous immunization converts subsequent and established antigen-specific $\mathrm{T}$ helper type 1 (Th1) to Th2-type responses. Immunology. 2006;119:2735.

51. Strid J, Hourihane J, Kimber I, Callard R, Strobel S. Disruption of the stratum corneum allows potent epicutaneous immunization with protein antigens resulting in a dominant systemic Th2 response. Eur J Immunol. 2004;34:2100-9.

52. Klechevsky E, Morita R, Liu MC, Cao YY, Coquery S, Thompson-Snipes L, et al. Functional specializations of human epidermal langerhans cells and CD14(+) dermal dendritic cells. Immunity. 2008;29:497-510.

53. Bursch LS, Wang L, Igyarto B, Kissenpfennig A, Malissen B, Kaplan DH, et al. Identification of a novel population of Langerin (+) dendritic cells. J Exp Med. 2007;204:3147-56.

54. Ginhoux F, Collin MP, Bogunovic M, Abel M, Leboeuf M, Helft $\mathrm{J}$, et al. Blood-derived dermal langerin + dendritic cells survey the skin in the steady state. J Exp Med. 2007;204:313346.

55. Poulin LF, Henri S, de Bovis B, Devilard E, Kissenpfennig A, Malissen B. The dermis contains langerin + dendritic cells that develop and function independently of epidermal Langerhans cells. J Exp Med. 2007;204:3119-31.

56. Slutter B, Soema PC, Ding Z, Verheul R, Hennink W, Jiskoot W. Conjugation of ovalbumin to trimethyl chitosan improves immunogenicity of the antigen. J Control Release. 2010; 143:207-14. 